\title{
OPTIMIZATION OF THE PREPARATION OF POLYPHOSPHATE COACERVATES USED AS GLASS PRECURSORS.
}

\author{
F. GOMEZ, P. VAST \\ Laboratoire de Chime Appliquée - Université des Sciences et Technologies de Lille \\ Bât C4 1 $1^{\text {¿ }}$ étage 59655 Villeneuve d'Ascq Cedex France
}

\begin{abstract}
The coacervation of polyphosphates permits to formulate a glass precursor in aqueous media and at ambient temperature. This reaction, which consist on a phase separation is induced by an addition of electrolyte or by a modification of the solvent properties. It depends on different parameters which are not yet entirely controlled. Some previous interpretation of this phenomenon are also inadequate. We have studied the influences of the chain length of the polyphosphates, of the solvent properties and of the electrolytes used. The results obtained indicate the possibility of coacervate achievement by univalent cation supply. They also permit an optimization of the process, for the choices of the commercial compounds, of the electrolytes and of the solvent.
\end{abstract}

\section{INTRODUCTION}

Metaphosphate glasses may present some interests for different applications because of theirs low glass transition (Tg) and melting $\mathrm{Tm}$ ) temperatures and their high coefficients of thermal expansion (CTE) ${ }^{1}$. For example, they may be used for metal enameling or for metal/ceramic sealing. For this kind of application, metaphosphate glasses are generally obtained by heating hydrogenophosphate powders ${ }^{2}$. But this route starting from metaphosphate glasses may present some disadvantages for coating or sealing processes. In those cases, a soft chemistry route, like sol-gel, is interesting. It is the reason of the development in our laboratory of a process like the sol gel route. Unfortunately, phosphates do not give condensation reactions in solutions. So that, we have to start from polyphosphates if we want to use this kind of process. Only the sodium salt is soluble and only in water. We start from a commercial sodium polyphosphate glass, which is no expensive (Graham's salt). By change of the chemical characteristics of the polyphosphate solution (electrolyte addition or modifications of the solvent properties), a miscibility gap appears with formation of a two phases system. The phase the more dense is called coacervate ${ }^{3}$. It contains water, polyphosphate chains and cations. This coacervate of polyphosphates is a glass precursor and it may be used as a glue for sealing process or by dipping, brushing or spraying for coating processes. Drying and vitrification are obtained after heating of the compound. The glass

Received September 10, 1999; Accepted April 3, 2000 
is directly formulated, to adapt its specific characteristics ( $\mathrm{Tg}, \mathrm{Tm}$, and $\mathrm{CTE}$ ), during the coacervation stage.

Nevertheless, in the previous old works of the laboratory, some approximations have been used to explain the coacervate formation. For example from thermal analysis, we have proposed the presence of different kinds of water in these coacervates ${ }^{4}$. But using a new technique of thermal analysis ${ }^{5-6}$, we have showed the presence of only one kind of water and the absence of stable hydrates. This result is very important for the drying of these glasses precursors. In the same way, the coacervation phenomenon was supposed to occur only with the addition of multivalent ion ${ }^{7}$. But in fact, coacervates may be obtained with only an addition of alcalin ions ${ }^{3}$. Contrary to ${ }^{7}$, it also appears that the $\mathrm{pH}$ of the solution is a minor parameter for the coacervate formation ${ }^{3}$.

We present our results about the influence of the main parameters for coacervation of polyphosphates. We have characterize the effects of the chain length of polyphosphates, of the solvent properties and of the nature of cationic species used.

\section{THEORY AND EXPERIMENTAL}

The term coacervation has been introduced to describe the phenomena observed in aqueous solutions of hydrophilic colloids. Literally, coacervation consists of interactions between polymeric particles, which induce the formation of aggregates. It is a phase separation of a solution of polyelectrolyte(s). The coacervate corresponds to the phase the more dense. It is a viscous liquid, between a sol and a precipitate. Coacervation is the results of electrostatic and hydration forces between polymeric particles. So that, the size of the colloid is an important parameter. In our case, we use sodium polyphosphate as polyelectrolyte and we induce coacervation by cations supplies or by modification of the solvent properties.

To define the conditions of coacervation in the system \{solvent - sodium polyphosphate electrolyte\}, solutions of Graham's salt, of various concentrations, are initially prepared. These one are placed into a thermostated vessel. Temperature is controlled by circulating water, using a thermostatic bath [LKB 2219 Multitemp II], with an accuracy of $+/-0.2{ }^{\circ} \mathrm{C}$. Solution is continuously stirred while an electrolyte solution, of known concentration, is added, until coacervation begins. Molar percentages of water, sodium poly-phosphate and electrolyte are then calculated. 


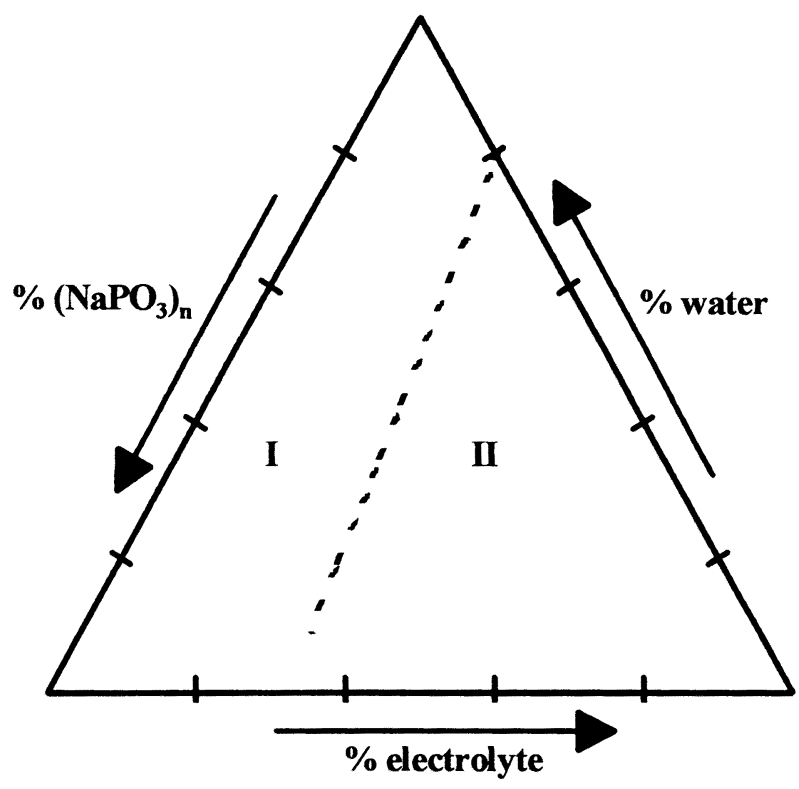

FIGURE 1 Graphical representation of critical conditions of coacervation.
We present our
results by an usual
graphical representation

The experimental values,

for the beginning of coacervation are plotted into a ternary diagram \{water - sodium polyphosphate $\left(\mathrm{NaPO}_{3}\right)_{\mathrm{n}}$ electrolyte\} (figure 1). A line separate the diagram in two areas. The first one (I), for the weak percentages of electrolyte, correspond to the compositions for which a stable solution exist. The second one (II), corresponds to two-phases systems \{coacervat / equilibrium liquid\}.

\section{RESULTS AND DISCUSSION}

We have studied the influence of the chain length of polyphosphates on the coacervation. Commercial compounds correspond to a mixture of different chain length. In order to modelise the influence of this chain length, we have prepared Graham's salts $\left(\mathrm{NaPO}_{3}\right)_{n}$ with controlled chain length $(\mathrm{n})$ by heating sodium hydrogenophosphates. The average value of $\mathrm{n}$ has been determined by ${ }^{31} \mathrm{P}$ NMR. Figure 2 presents the results obtained for coacervation of four different Graham's salts. Coacervation is here obtained by addition of calcium chloride.

It appears that the critical conditions of coacervation don't depend on the chain length of polyphosphates. Nevertheless, the highest concentration of $\left(\mathrm{NaPO}_{3}\right)_{\mathrm{n}}$ which permits the coacervation increases with the increase of the chain length of the polyelectrolyte. This is an important result because the yield of reaction depend on the concentration of the system. 
In the same way, we have studied different commercial Graham's salts (figure 3). The results obtained are in accordance with the previous modelisation for controlled chain lengths.

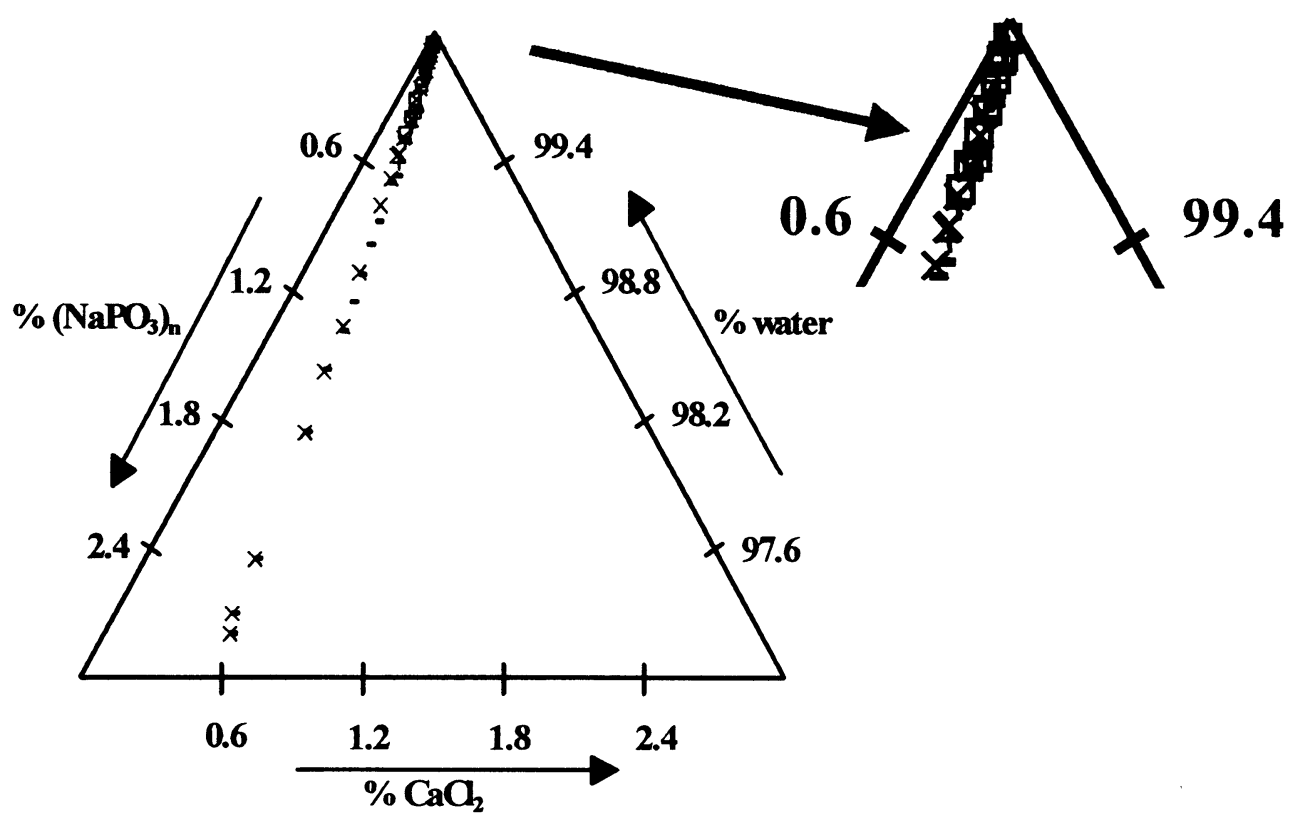

FIGURE 2 Critical conditions of coacervation for several sodium polyphosphates $\left(\mathrm{NaPO}_{3}\right)_{\mathrm{n}} . \quad \square \mathrm{n}=3.2+\mathrm{n}=18.1 \quad-\mathrm{n}=27.9 \quad \times \mathrm{n}=52.5$

In order to optimize the reaction of coacervation, we have used the commercial sodium polyphosphate [Merck] for the next experiments. It is in fact the compound which permits coacervation for the highest concentration of polyelectrolyte (table I).

Table 1 Highest concentration of sodium polyphosphate which permits the coacervation, for several commercial compounds $\left(\mathrm{mol} . \mathrm{l}^{-1}\right)$.

\begin{tabular}{ccc}
\hline$\left[\left(\mathrm{NaPO}_{3}\right)\right]_{\max }$ & {$\left[\left(\mathrm{NaPO}_{3}\right)\right]_{\max }$} \\
$($ Merck : $\mathbf{n = 2 3 . 0 )}$ & $($ Europhos : $\mathbf{n = 1 8 . 0 )}$ & $\begin{array}{c}{\left[\left(\mathrm{NaPO}_{3}\right)\right]_{\max }} \\
\text { (Aldrich : } \mathbf{n = 9 . 4 )}\end{array}$ \\
\hline 2.7 & 2.0 & 0.3 \\
\hline
\end{tabular}




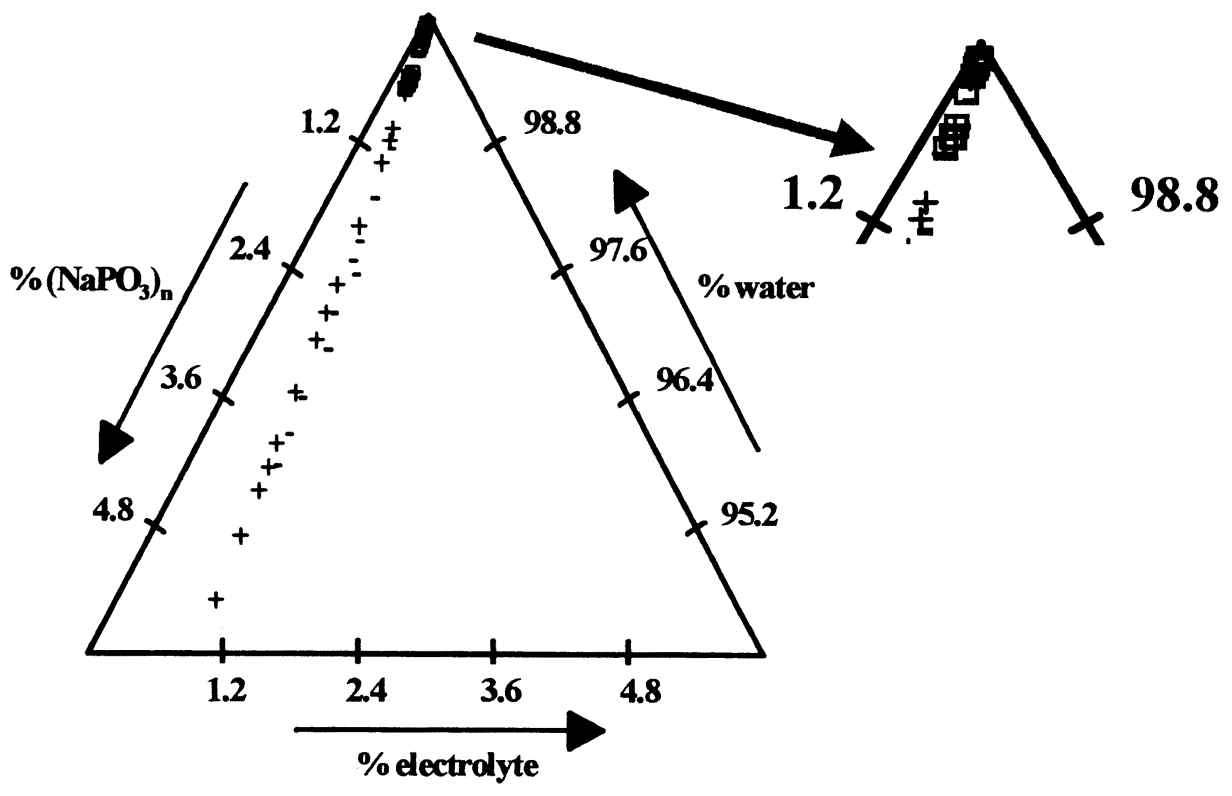

FIGURE 3 Critical conditions of coacervation for several commercial sodium polyphosphates. + Merck $n=23$ - Europhos $n=18$ Aldrich $n=9.4$

The nature of the solvent is important during the coacervation, because of the dielectric constant of the system and because of specific interactions of solvation. Sodium polyphosphate is only soluble ion water. Nevertheless, we may start from mixtures of water with few amounts of ethanol as solvents. Figure 4 shows the results obtained for several quantities of ethanol introduced into the initial solutions of (NaPO3)n [Merck] and of calcium chloride.

The addition of ethanol favors the formation of coacervate. We may also directly obtain the coacervation without calcium chloride addition, for large amounts of ethanol. For example, for a concentration of sodium polyphosphate of $3.6 \%$ (mol.), coacervate appears if the dielectric constant of the system is less than 77.7 (figure 5) values of $\varepsilon_{\mathrm{r}}$ calcium chloride have to be added. The percentage of $\mathrm{CaCl}_{2}$ needed for coacervation increases with the increase of the dielectric constant. It appears that the reaction of coacervation may be optimized (reduction of the quantities of electrolyte used) by supply of few amounts of a poor solvent such as ethanol. 


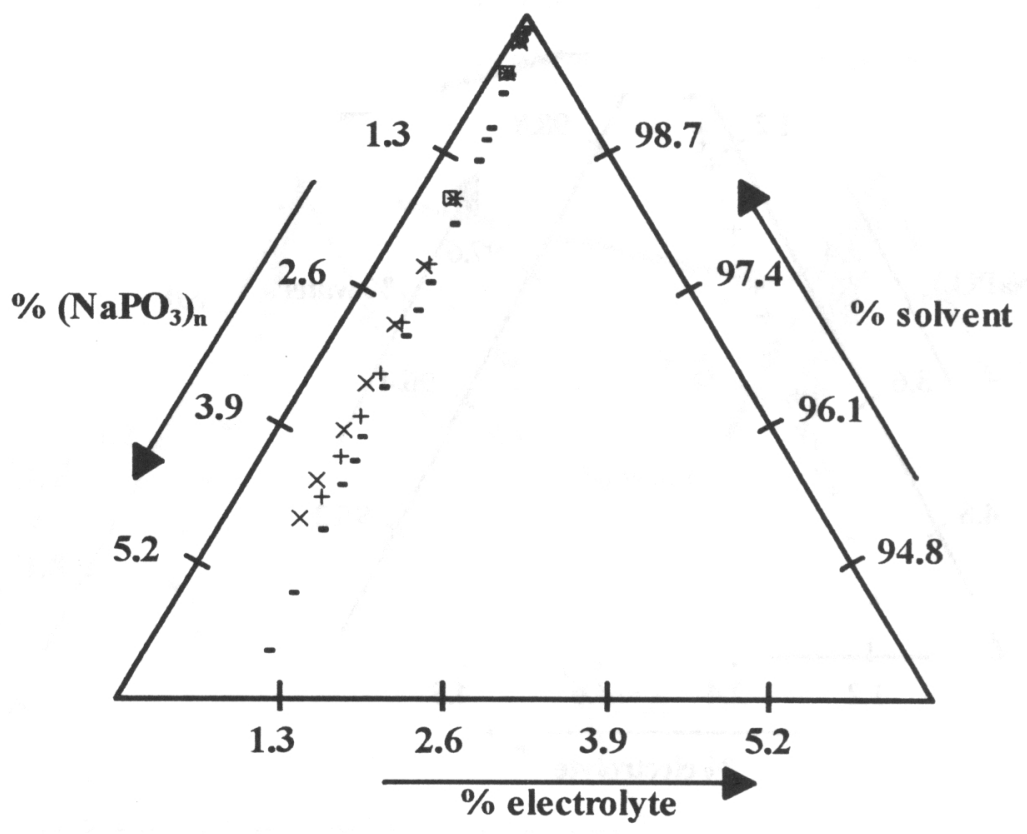

FIGURE 4 Critical conditions of coacervation for several commercial sodium polyphosphates. $-\varepsilon_{\mathrm{r}}=78.5+\varepsilon_{\mathrm{r}}=78.1 \quad \times \varepsilon_{\mathrm{r}}=77.8 \quad \square \varepsilon_{\mathrm{r}}=77.0$

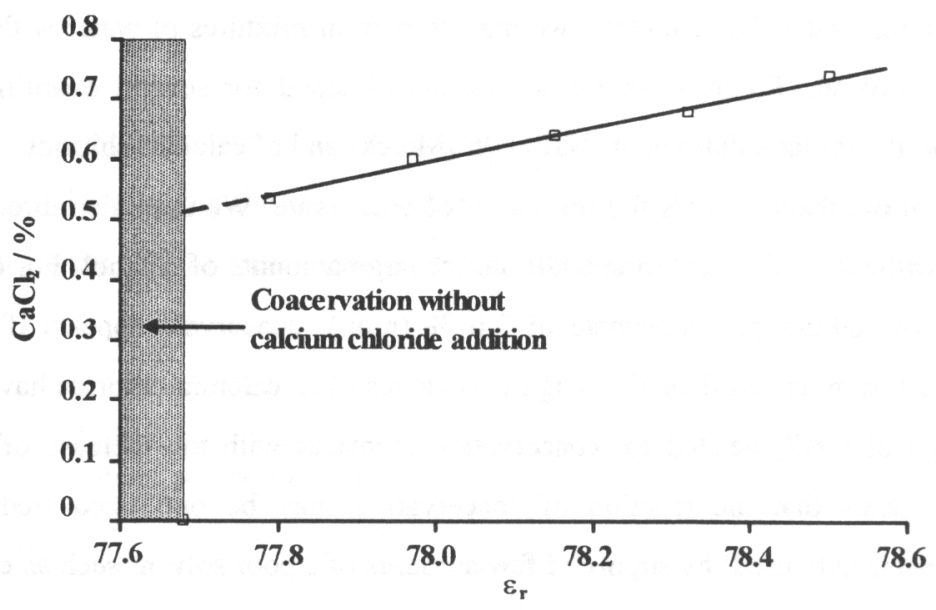

FIGURE 5 Critical concentration of $\mathrm{CaCl}_{2}$ needed for the coacervation of a $3.6 \%$ $\left(\mathrm{NaPO}_{3}\right)_{\mathrm{n}}$ system versus the dielectric constant of the solvent.

Coacervation is explained by electrostatic interactions between polyelectrolytes. Interaction between polyphosphates are repulsive. Their intensity is decreased when a cation is added, and 
coacervation occurs. So that, the valence of the cation is important. The critical concentration of cationic species is very different for univalent and divalent cations (figure 6).



FIGURE 6 Critical conditions of coacervation for several electrolytes.

$$
\Delta \mathrm{CaCl}_{2}+\mathrm{MgCl}_{2} \quad \square \mathrm{FeCl}_{2} \times \mathrm{NaCl}
$$

Nevertheless, the critical concentration of electrolyte also depend on the nature of the cation, as shown in table II. The electrolyte used to induce coacervation may then been chosen from economic or technologic criteria.

Table 2 Minimum volumes of $2 \mathrm{M}$ electrolyte solutions which have to be added to $200 \mathrm{ml}$ of a $3 \mathrm{M}\left(\mathrm{NaPO}_{3}\right)_{\mathrm{n}}[\mathrm{Merck}]$ solution to obtain a coacervate $(\mathrm{ml})$.

\begin{tabular}{cccc}
\hline $\mathrm{V}_{\min }\left(\mathrm{MnCl}_{2}\right)$ & $\mathrm{V}_{\min }\left(\mathrm{CaCl}_{2}\right)$ & $\mathrm{V}_{\min }\left(\mathrm{MgCl}_{2}\right)$ & $\mathrm{V}_{\min }\left(\mathrm{FeCl}_{2}\right)$ \\
\hline 57 & 61 & 65 & 69 \\
\hline
\end{tabular}

Some authors explain the coacervation of polyphosphates by intramolecular interactions between a divalent cation and the polyelectrolyte ${ }^{10}$. Nevertheless, we show that coacervates may been obtained by addition of only alcalin ions. 


\section{CONCLUSION}

We have shown that the chain length of polyphosphates have an important influence on the yield of coacervation. So that, commercial Graham's salts may be chosen carefully. By ethanol supply into the system, the quantities of electrolyte needed to obtain the coacervate are reduced. This may permit to optimize the reaction. Contrarily to previous studies, we have also shown that polyphosphate coacervates may be obtained by an addition of univalent cation.

\section{REFERENCES}

1. R.C. Ropp, in Inorganic Polymeric Glasses, Edited by Elsevier (New York, 1992).

2. T. Kanazawa, in Inorganic Phosphate Materials, Edited by Elsevier (New York, 1989).

3. F. Gomez, P. Vast and F. Barbieux, Phosphorus Res. Bull., 5143 (1995).

4. A.M. Bera, Ph. Thesis, Lille : USTL (1986).

5. F. Gomez, P. Vast, A.M. Bera, F. Barbieux, Ph. Llewellyn, F. Rouquerol and T. Miyajima, Calorim. Anal. Therm., 26357 (1995).

6. F. Gomez, P. Vast, Ph. Llewellyn and F. Rouquerol, J. Anal. Therm., 491171 (1997).

7. M. Draoui, $\mathrm{Ph}$. Thesis, Lille : USTL (1985).

8. G. Weis, A. Knoch, A. Laicher, F. Stanislaus and R. Daniels, Int. J. Phar, 12487 (1995).

9. P. Souchay, in lons minéraux condensés / Condensed mineral ions, Edited by Masson \& Cie (Paris, 1969).

10. R. Pfanstiel and R.K. Iler, J. Am. Chem. Soc., 785510 (1956). 